\title{
EL COMERCIO DEL PASTEL. \\ DATOS PARA UNA GEOGRAFIA \\ DE LA INDUSTRIA PAÑERA ESPAÑOLA \\ EN EL SIGLO XVI
}

\author{
HILARIO CASADO ALONSO \\ Universidad de Valladolid
}

En este trabajo se analizan las características del comercio en el siglo xvi de uno de los principales colorantes empleados en la industria pañera: el pastel. Dicho producto fue una de las más principales mercancías intercambiadas durante fines de la Edad Media y principios de la Moderna. En dicho tráfico sus mayores participantes en toda Europa fueron los mercaderes españoles, y en especial los burgaleses. En el trabajo se reconstruye dicho comercio en España a partir de los datos de unos 2.000 asientos de compra venta de pastel procedentes de diversos Libros de Cuentas Mercantiles. Dichas cifras permiten presentar un completo panorama de la geografía de la industria pañera española durante el siglo xvi: su jerarquización según su importancia económica, sus características productivas, la diferenciación entre los centros rurales y los urbanos, las redes de comercialización, etc.

\section{INTRODUCCION}

La industria pañera medieval y moderna, además de la lana, empleaba toda una serie de materias colorantes con las cuales teñir la fibra en bruto, en hilo o en tejido. Para ello, bien se hiciera en cualquiera de estas tres fases del proceso de fabricación, se utilizaban fundamentalmente diversos productos vegetales con los cuales obtener los cinco colores básicos y, con posterioridad, las tonalidades compuestas. Con esta finalidad se usaron una multitud de sustancias colorantes, unas autóctonas, otras exóticas, unas más caras, otras de peor calidad, etc. Algunas de ellas son el pastel, la roja o rubia, el brasil, la grana, la urchilla o cochinilla, el zumaque, el ferrete, la gualda, el torvisco, el metapol, la cendra... Destacan las cuatro primeras, a las que a partir de mediados del siglo xvi se sumaron los tintes procedentes de América '. Yo aquí abordaré el estudio de la primera, que, como veremos más tarde, fue fundamental en la artesanía textil.

' De Poerck (1951), vol. I, pp. 150-198; Iradiel (1974), pp. 175-186. 
El pastel se obtiene del cultivo de la planta del glasto (isatis tinctoria), cuyas hojas son ricas en glucósidos de indoxilo, de los cuales la sustancia colorante, el índigo o indigotina, es un derivado tintóreo con el que se consigue la tonalidad azul. Para ello, una vez recogidas y lavadas, se trituraban y se fermentaban, consiguiéndose un polvo de color oscuro. Este era empaquetado en balas de tela de cañamaza, generalmente de peso semejante y con diferentes marcas según fuera su propietario, origen y calidad. A partir de ese momento podía ser comercializado por los mercaderes del pastel en los diferentes centros textiles.

El antedicho proceso, como ha estudiado G. Caster, exigía por parte de éstos una fuerte capitalización, ya que desde que se sembraba la planta hasta la venta final del tinte pasaban cerca de dos años y a ello había que sumar cuantiosos gastos de obtención, amén de pérdidas en caso de rupturas o mojaduras de los paquetes. Ello hizo que el comercio del pastel estuviera en manos de unas pocas personas y compañías lo suficientemente ricas como para soportar las fuertes reservas financieras que habían de hacerse ${ }^{2}$.

El pastel era utilizado en la industria pañera para conseguir, como se ha dicho, el color azul con sus diferentes tonalidades, que iban desde el azul claro hasta el azul subido, casi negro, ya que todavía no se conocía la tintura específicamente negra. De igual manera, al ser un tinte básico era necesario para obtener colores secundarios mediante su posterior teñido con otras sustancias, demudándose el paño. Ello se traducía en que prácticamente todos los tejidos que no fueran blancos eran teñidos con pastel, especialmente - tal como sostienen diversas ordenanzas - aquellos que eran de calidad media y alta. Pero, aparte de todo esto, el pastel presentaba una ventaja sobre el resto de los colorantes: podía ser aplicado directamente sobre las fibras de lana o el paño entero, sin necesidad de recurrir a una preparación previa con la utilización de mordientes, en especial el alumbre.

Estas características del pastel hicieron que su consumo durante la Edad Media y el siglo xvi estuviera muy desarrollado, al necesitarse el empleo de grandes cantidades de dicho producto en el teñido de los tejidos. Amén de ello, en aquellos años el color azul y sus diversas tonalidades — sobre todo el púrpura - era el más solicitado en la alta pañería y la moda.

Este alto consumo ${ }^{3}$ hizo que su cultivo y producción estuvieran muy extendidos por toda Europa. Sin embargo, si se quería que tuviera un fuerte poder tintóreo - - expresado en su ley en florines- era necesario utilizar el

Caster (1962), pp. 78-86.

${ }^{3}$ Angel García Sanz ha calculado que el consumo de pastel suponía para los fabricantes de paños segovianos uno de sus principales gastos, tanto en términos globales como en relación con los materiales consumidos en el proceso productivo. García Sanz (1987), pp. 74 y 77. 
abtenido de plantas de calidad. Esto motivó que durante los siglos xv y xvi hubiera dos zonas de más intenso cultivo y comercialización: la región de Toulouse, que era la que producía el mejor pastel y abastecía a gran parte de las industrias textiles mediterráneas y noroccidentales; y el obtenido de las islas Azores, más moderno y de una menor producción.

En suma, el pastel durante la Edad Media y el Quinientos fue una de las materias colorantes más utilizadas en la pañería europea. No obstante, su esplendor duró hasta las décadas de los años sesenta y setenta del siglo xvi, cuando la irrupción del añil americano, del cual se obtenían tonalidades azules de mejor calidad y a menores precios, arruinó su cultivo y comercialización.

\section{EL COMERCIO DEL PASTEL EN ESPAÑA}

El uso del pastel en la industria textil española durante la Edad Media estuvo muy difundido. P. Iradiel ha constatado su empleo en diversos centros pañeros e, incluso, su cultivo en la región de Murcia, aunque señala que en su mayor parte era importado ${ }^{4}$.

Así sabemos que dicho producto figuraba entre los que vendían los mercaderes genoveses, los cuales monopolizaban en 1396 la casa y las tasas de los tintes de Murcia, dando lugar a quejas de los pelaires locales, situación que perdurará a lo largo del siglo $\mathrm{xv}^{5}$.

Yo, por mi parte, he comprobado que en dicho comercio durante los siglos XIV y XV participaron activamente los mercaderes burgaleses. Así, en 1377, un tal Martí Sancho de Santa Cruz, traficante de la ciudad del Arlanzón, aparece haciendo negocios en Toulouse, quizá de dicho producto ${ }^{6}$. Ya en la centuria siguiente, en esta misma urbe - convertida en el principal centro pastelero de Europa-, el profesor $G$. Caster ha constatado la presencia de numerosos personajes de Burgos: Diego de Bernuy Dávila, Diego y Juan de Castro, García de Mazuelo, Rodrigo de Frías, Rodrigo de Valladolid, María López de Vitoria y sus hijos, Juan de Valpuesta, Rodrigo de Salazar, Rodrigo de Burgos, Martín de Maluenda, Juan de Miranda, Juan Pardo, Alonso de Santo Domingo... De hecho, afirma él mismo que desde 1475 a 1510 los compradores de pastel tolosano son, sobre todo, llegados de Burgos ${ }^{7}$.

Los comerciantes naturales de la Cabeza de Castilla no sólo traficaban con dicho producto tintóreo para importarlo a la península, sino también para

- Iradiel (1974), pp. 179-181.

3Torres Fontes (1976), pp. 69-168.

- Wolff (1954), p. 158.

7 Caster (1962), pp. 91-124. 
exportarlo a otros centros textiles europeos. El estudio de 207 pólizas de seguros marítimos firmadas en el período comprendido entre 1481 y 1508 me ha permitido comprobar que 27 de éstas tenían por carga balas de pastel que diferentes navíos transportaban desde el puerto de Burdeos a Londres, Irlanda, Flandes y Gelanda ${ }^{8}$. Más reveladores son los datos del movimiento del puerto de Burdeos desde 1470 hasta 1520 publicados por J. Bernard Según ellos, la mayor parte de los comerciantes del pastel con destino a Inglaterra y Flandes eran españoles, y entre ellos muchas familias burgalesas y la bilbaína de los Arbieto. Este mismo hecho también aparece reflejado en las cuentas que ante el Consulado de Burgos presentó el bolsero de la Nación Española en Flandes. Este anotó en el período de 1523 a 1525, junto a diversas cantidades de sacas de lana, costales de hilaza, peletería, pimienta, grana, clavo, regaliz y fardeles de seda, la llegada a dichos puertos de 7.033 balas de pastel ${ }^{10}$. Todas estas informaciones nos hablan de manera clara acerca del gran desarrollo que ha alcanzado el comercio burgalés durante el reinado de los Reyes Católicos. Según ellas, podemos decir sin ninguna duda que los mercaderes de Burgos controlaban el tráfico del pastel en gran parte de Europa. No en vano el intercambio de dicho colorante, lo mismo que el del alumbre, era el complemento ideal de su gran mercancía, la lana, al ser todas materias primas para la industria textil ${ }^{11}$.

Este comercio del pastel por parte de gente burgalesa o vinculada a los mercaderes de dicha ciudad alcanza su cenit en el siglo xvi. Así, las cuentas de 1518-1519 de Diego de Ordónez, mercader y clérigo de Avila, señalan, aparte de negocios de cambios y tejidos, operaciones con tintes. No en vano, éste era el sobrino de los grandes comerciantes del pastel, Diego de Bernuy Dávila y Jean de Bernuy. Al igual que ellos, su lugar de aprovisionamiento era Toulouse, y como medio de pago utilizaba, también, letras de cambio giradas sobre las ferias de Lyon con la familia Nasi ${ }^{12}$.

En el Quinientos eran numerosos los mercaderes burgaleses que traficaban con dicho colorante. Tengo noticias de tratos efectuados por miembros de las principales familias de la oligarquía urbana de la Cabeza de Castilla:

- Como consignatarios de cargazones de pastel aparecen Hernando de Castro, Alonso de Aranda, Alvaro de Santa Cruz, Diego de Soria, Alonso de Lerma, Pedro de Quintanadueñas, Alvaro de la Torre, Lope de Sanvitores, Alonso de Maluenda, Francisco Orense, Sancho de Saldaña, los Polancos, Alonso de Salamanca, Diego de Castro, Alonso de Maluenda, Alvar García de S. Millán y Diego de Bernuy. Casado Alonso (1989).

${ }^{9}$ Bernard (1968), vol. III.

${ }^{10}$ Archivo Diputación Provincial de Burgos, Consulado, Libro núm. 1, Libro de Cuentas de la Universidad de Mercaderes de Burgos (1509-1539), ff. 50-58'.

"La participación de burgaleses en el comercio de otros tintes diferentes al pastel fue menor. Para el siglo xvi sólo tenemos algunos datos de importación de rubia de Flandes y de exportación de grana a Brujas.

${ }_{12}$ Alvarez García (1988). 
el regidor Martín Alonso de Salinas, Alonso y Miguel de Salamanca, Juan de Astudillo, Alonso de Polanco, Juan de Castro, Juan Velázquez, Jerónimo y Diego de Medina, Juan de Oñate, Alvaro de Cuevas, Diego Ximénez, Diego López Gallo, Alonso Gutiérrez de Sanvitores, Pedro y Alonso de Arlanzón, etcétera ${ }^{13}$. De la misma forma, fueron burgaleses los principales comerciantes de pastel en los puertos de la fachada atlántica europea ${ }^{14}$.

Pero, independientemente de estas noticias ${ }^{15}$, yo aquí voy a analizar los caracteres del comercio del pastel a través de los negocios de dos mercaderes de mediados de la centuria: Juan de Lerma y Diego de Bernuy Orense. Para ello contamos con una fuente valiosísima, pero poco utilizada, para la Historia Económica: los libros de contabilidad mercantil. En concreto, tres Libros Manuales (Diarios) de gran tamaño y de formato semejante a los conocidos de otros traficantes ${ }^{16}$. El primero pertenece a Juan de Lerma y abarca desde 1541 hasta $1551{ }^{17}$. Los restantes son de Diego de Bernuy Orense, compren. diendo desde 1546 hasta 1555, aunque sólo están completas las cuentas hasta el año 1550 , inclusive ${ }^{18}$. Todos han pasado casi inadvertidos por los investigadores, ya que al no figurar en sus portadas el nombre de sus titulares han sido dejados de lado ${ }^{19}$. En ellos aparecen en torno a unos 2.000 asientos de compraventa de pastel, amén de otros referentes a pagos, gastos, etc., derivados de dicha actividad.

Estos tres libros de contabilidad nos dan, pues, una inmejorable aproximación a dicho comercio en España e, incluso, del resto de Europa. Sus visiones, aunque convergentes, parten de los casos de mercaderes de distinta condición. El primero, Juan de Lerma, es el representante de una familia de comerciantes que podríamos calificar de tipo medio-alto. Es miembro de una de las más antiguas dinastías de la ciudad, cuyos orígenes se remontan al siglo xIv, muy poderosa en la centuria siguiente, pero que en el siglo xvI podemos decir que ha venido a menos. Su contabilidad refleja la enorme diversidad de tratos e intercambios de los mercaderes burgaleses: ventas de

${ }^{3}$ Archivo General de Simancas, Consejo Real, Legajo 94-1; ADPB, Consulado, Libros núms. 1 y 9, y García Sanz (1987), p. 77.

it Jones Mathers (1988) y Brunelle (1989).

15 De muchos de estos mercaderes burgaleses desconocemos el volumen de sus negocios de pastel. Sólo tengo datos de la compañía de Miguel y García de Salamanca, los cuales en 1553 vendieron por valor de $497.955 \mathrm{mrs}$. [ADPB, Consulado, Libro núm. 9, Libro de Caja (Mayor) de García de Salamanca (1552-1563), f. 80].

${ }^{16}$ González Hernando (1983) y Hernández Esteve (1988).

17 ADPB, Consulado, Libro núm. 2, Libro Manual (Diario) de Juan de Lerma (15411551), 127 folios $(445 / 295 \mathrm{~mm})$.

${ }_{18}$ ADPB, Consulado, Libro núm. 4, Libro Manual (Diario) de Compras de Diego de Bernuy (1546-1555), 314 folios (440/300 mm), y Libro núm. 5, Libro Manual (Diario) de Diego de Bernuy (1548-1550), 182 folios (440/290 mm).

${ }_{19}$ Los únicos trabajos hechos a partir de cllos son los de la profesora canadiense S. Barkham/Huxley. 
sacas de lana en Flandes y Rouen, seda en Lyon, importación de telas de Londres, Flandes y Bretaña, etc. Sus negocios con el pastel eran modestos, consistiendo sus ventas, por ejemplo en 1546 , en 479,5 cargas por un valor de 1.461 .690 mrs. ${ }^{20}$.

El caso de Diego de Bernuy Orense es muy diferente. El y sus socios formaban una de las principales compañías comerciales de Castilla y Europa del siglo xvI ${ }^{21}$. De igual manera eran los mayores traficantes del pastel de toda Europa en dicha centuria. Su contabilidad arroja como valores medios para los años 1546-1550 la fabulosa cifra de ventas en la península de 9.655,9 cargas (1.729 toneladas) por una suma de 44/45 millones de maravedís anuales. A estas cantidades habría que sumar otras 6.000 cargas vendidas en Flandes y Londres. Esta hegemonía la han ido consiguiendo, según las cifras del movimiento de mercancías del puerto de Burdeos, desde principios de siglo ${ }^{22}$. Las fuentes burgalesas confirman dicha situación, siendo para las autoridades del Consulado la compañía de los Bernuy la más importante de Castilla ${ }^{23}$.

Originarios de Avila y muy posiblemente conversos, emigraron en el último tercio del siglo $\mathrm{xv}$ a Burgos y Toulouse, constituyendo a partir de entonces los hermanos Diego de Bernuy Dávila y Jean de Bernuy una perfecta sociedad que llegó a controlar gran parte del comercio del pastel tolosano, al que posteriormente añadieron el procedente de las islas Azores. Tal como ha afirmado $G$. Caster para el caso de la rama francesa y yo para la española, fueron sin duda los mayores comerciantes de dicho tinte en toda Europa, creando lo que se ha venido en denominar un "sistema completo". Controlaban el cultivo de la planta, su transformación y exportación, contando para ello con una complejísima red comercial y financiera.

Por ello creo que, sin duda, dominaron el mercado español, siendo el resto comerciantes del pastel de menor tamaño e, incluso, clientes suyos. De ahí que en el presente trabajo me ceñiré al estudio de los intercambios de la familia Bernuy a lo largo de los años 1546-1550 en España ${ }^{24}$ y, en menor medida, en los de Juan de Lerma. La hegemonía, incluso el casi mono-

\footnotetext{
20 ADPB, Consulado, Libro núm. 2, ff. 48'-58.

21 La historia y la valoración económica de esta compañía puede verse en Casado Alonso (en prensa, a).

22 Bernard (1968), vol. III.

${ }^{23}$ Esta situación es válida no sólo para el comercio del pastel, donde, por ejemplo, en 1525 había importado la más elevada cantidad de dicho colorante ( 1.198 cargas a Flandes y Londres, y 3.459 a Castilla), sino para el conjunto de negocios. Así, en 1543, Diego de Bernuy y su madre, Isabel Orense, contribuyeron en la derrama que la Universidad de Mercaderes hizo para prestar al monarca 22.500 ducados con $687.000 \mathrm{mrs}$. (el 8,7 por 100), la cifra más alta de todas (ADPB, Consulado, Libro núm. 1, f. 59, y Libro núm. 3, ff. $66 \mathrm{y}$ ss.).

${ }_{24}$ Para el resto de los negocios, véase Casado Alonso (en prensa, $a$ ).
} 
polio, que el primero tenía sobre el comercio de dicho colorante permite extraer conclusiones para el conjunto de la pañería peninsular. Sin embargo, estos datos han de tomarse de manera indicativa de la situación de aquellos años, especialmente en las zonas centro y norte. Por el contrario, al ser menor la presencia de los mercaderes burgaleses en Andalucía, las conclusiones para los centros pañeros meridionales son relativas ${ }^{25}$. No obstante, aunque con todas las matizaciones posibles, el panorama que ofrecen estos libros de contabilidad es esclarecedor de la geografía de la industria pañera española.

\section{LA ORGANIZACION DEL COMERCIO DEL PASTEL DE LA COMPAÑIA BERNUY}

Como se ha dicho, las cuentas de Diego de Bernuy Orense, hijo y sobrino, respectivamente, de Diego de Bernuy Dávila y de Jean de Bernuy, ofrecen una información muy numerosa y valiosa. A través de ella podemos seguir a la perfección, casi día a día, las diversas operaciones y circunstancias que acontecían desde el envío de las balas de pastel desde los centros productores hasta su venta a los tejedores y tintoreros.

\subsection{Zonas de aprovisionamiento del pastel}

Tanto en el caso de Juan de Lerma como en el de Diego de Bernuy, éstos adquieren el colorante en dos zonas: Toulouse y Lisboa. La primera de ellas es la más importante, representando para el segundo mercader el 86 por 100 del total de sus importaciones en España. Ello no es extraño si tenemos en cuenta que dicha ciudad era el principal centro productor de pastel de Europa y allí contaban con la presencia destacada de sus socios, Jean de Bernuy y Pedro de San Esteban.

El glasto adquirido en Toulouse por la compañía era enviado a los diversos puntos de Europa. Desde Burdeos, el puerto fundamental de embarque, a Amberes, Londres y Castilla. En este último caso, a Santander, Laredo y Bilbao y, en ocasiones, a Cartagena y Valencia. Sin embargo, el comercio con destino a estas dos plazas se hacía preferentemente desde Narbona y Aigues-Mortes. Por vía terrestre, desde Toulouse se mandaban balas por Somport y Canfranc a Pamplona y Zaragoza.

${ }^{25}$ A este respecto llama la atención la ausencia de datos acerca de la pañería cordobesa. Ello, quizá, sea debido a que, como ha estudiado J. I. Fortea, sus tintoreros se abastecían, sobre todo, a través de comerciantes portugueses del pastel de Azores. Fortea (191), pp. 292-299. 
El pastel portugués, el denominado pastel de las yslas, era adquirido en Lisboa y, sobre todo, en las Azores, donde la compañía contaba con un agente, Juan del Oyo Espinosa. Desde allí se enviaba por barco hasta el puerto de Santander.

Para efectuar todo este transporte, los Bernuy contrataban los servicios de diferentes navíos, naos y ulcas - anualmente unos cuarenta y cinco, de los cuales treinta con destino a la península-, principalmente bordeleses y vascos. Sus cargazones iban aseguradas, siendo estos gastos uno de los más elevados en el comercio del colorante. Así, en 1546, para Diego de Bernuy los seguros marítimos del pastel ascendieron a la suma de $708.518 \mathrm{mrs}$., resultantes de unas primas de 95.400 ducados.

\subsection{La comercialización del pastel: su redistribución}

Para la distribución y comercialización del pastel la compañía de los Bernuy contaba con una compleja y numerosa red organizativa. En los libros de contabilidad he registrado 19 personas que actuaban como criados y empleados en diferentes lugares y para diversas labores mercantiles (correos, encargados a pie de puerto de los embarques y desembarques, comisionados para el transporte y los asuntos de los carreteros, cajeros y contables, escribanos, recaudadores de deudas, etc.). A éstos hay que sumar los factores y/o socios que tenían en las diferentes plazas: Amberes, Londres, Nantes, Ruan, Burdeos, Lyon, Lisboa, Azores, Segovia, Cuenca, Toledo, Sevilla, Valencia y Zaragoza. Todos participaban de alguna manera en las diversas operaciones de redistribución del colorante, enviando periódicamente informes y cuentas a la sede central de la compañía en Burgos.

A través de ellos conocemos sus características. Uno de los trabajos más importantes y de costos elevados era el derivado de las labores del transporte marítimo. Junto al pago de los fletes a los maestres, había que desembolsar el coste de los seguros. A menudo, hubo discusiones entre los patrones de navíos y los Bernuy por deterioros en las cargazones y los problemas de extornos derivados de ellos. En general, los premios de los seguros del pastel eran altos al ser mercancías delicadas, aunque no tanto como los del vino. En el puerto había que realizar toda una serie de operaciones: la entrada, amarre y descarga de los navíos por gente especializada, con sus correspondientes derechos de barcaje y estolaje; el almacenamiento en lonjas determinadas o en ciertos locales; el remiendo con hilo de aquellas balas de cañamaza dañadas; la retirada del pastel que se hubiera mojado, etc. Amén de ello, en puerto se pagaban los tributos de diezmo de la mar, almojarifazgo, alcabala, portazgo y averías del Consulado. 
Para el transporte al interior del país — dado que las ventas a pie de puerto fueron escasas en relación al resto ${ }^{26}$ - la compañía contrataba los servicios de carreteros. Estos procedían fundamentalmente de la sierra de Burgos-Soria, donde se radicaba la importante Hermandad de Carreteros ${ }^{27}$. El sistema empleado era el señalamiento, mediante el cual los Bernuy alquilaban por adelantado de un año para otro las carretas mediante el pago de una señal. El número de vehículos empleados oscilaba entre 1.000 y 1.400 carretas anuales. Durante estos años 1546-1550, el coste de cada una de ellas era de un ducado.

Había varias rutas de transporte. La principal era la que partiendo de Bilbao/Santander se dirigía a Burgos y desde allí a Segovia, el centro redistribuidor del pastel en Castilla. Como accesoria era la de Bilbao a Ezcaray. Para las mercancías llegadas por el puerto de Cartagena el trayecto se dirigía por Murcia a Albacete, desde donde las carretas se bifurcaban en dirección a Toledo o a Cuenca. Una vez llegadas a su destino las balas de pastel se almacenaban en los locales que la compañía tenía a tal efecto y se procedía a su comercialización.

Antes de efectuar la venta, los Bernuy enviaban a sus posibles clientes una serie de muestras para mostrar la capacidad tintórea del pastel. Era lo que se denominaba el ensay. Cuando los hipotéticos compradores aceptaban dichas condiciones firmaban ante escribano público el contrato de compraventa, señalándose en él la cantidad adquirida, el tipo del pastel y las modalidades de pago. Estas últimas consistían frecuentemente en tres, cuatro y cinco plazos dentro del mismo año y el siguiente. Debido a ello se hacían cartas de obligación para pagar las diferentes cantidades bien en la ciudad del comprador, bien en las ferias de Medina del Campo y Villalón.

En ocasiones, las cuentas de los Bernuy reflejan que ciertos compradores no pudieron satisfacer el pago de sus deudas. Ante dicha situación se procedía al embargo de determinados bienes de los deudores, generalmente paños, que la compañía vendía en Sevilla, Medina del Campo o Burgos ${ }^{28}$.

\subsection{El espacio comercial del pastel}

Según los libros de contabilidad, la compañía de los Bernuy vendía el pastel por toda la península, pero de manera especial por ambas mesetas.

\footnotetext{
${ }^{26}$ Sólo son destacables las compras efectuadas en Bilbao por comerciantes de Orduña/ Riaza y vecinos de la zona de Ezcaray.

${ }^{27}$ Gil Abad (1983).

${ }^{28}$ En ocasiones, las sumas de estos embargos fueron muy elevadas. Así, en $1550 \mathrm{~cm}$ bargó a diversos vecinos de Segovia pañus por valor de $1.236 .100 \mathrm{mrs}$.
} 
Entre sus clientes los había de dos tipos. Por un lado, los más importantes - -en número y en compras- eran los artesanos o gentes relacionadas de alguna manera con la industria textil. Pero, por otra parte, estaban algunos mercaderes de diversa condición que adquirían el colorante a la sociedad y actuaban como intermediarios a pequeña escala. Este parece ser el caso de algunas personas de Burgos, como el regidor Martín Alonso de Salinas; el de Juan Aguado, vecino de Peñafiel y comerciante de rubia; el de ciertos comerciantes de Rioseco, Zaragoza, Valencia y Toledo; el inglés Roger Jofresun, residente en Bilbao, y Richarte Henteley, vecino de Bristol y S. Sebastián; y el más destacable de los Barahona de Orduña, que actuaban en asociación con los Bernardo y los Xuárez de Riaza.

El conjunto de ventas a los diversos clientes de la península está reflejado en el Apéndice I. En él he colocado, junto a cada localidad, el número de cargas de pastel vendidas y su valor en maravedís. Un resumen de las principales cifras puede verse en el cuadro 1.

\section{CUADRO 1}

Ventas de pastel de la compañia de los Bernuy (Valores medios de 1546-1550)

\begin{tabular}{|c|c|c|}
\hline Zonas & Cargas & Porcentajes \\
\hline 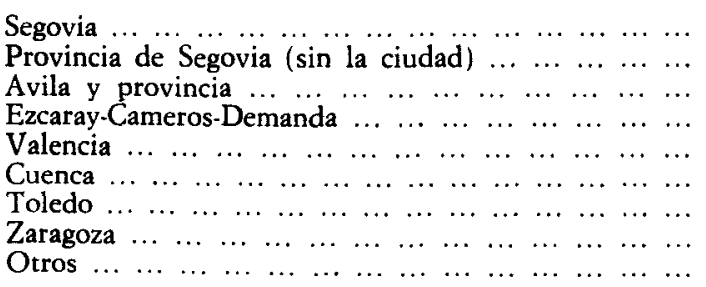 & $\begin{array}{r}5.011,1 \\
616,7 \\
314,5 \\
1.230,9 \\
785 \\
706,8 \\
391,9 \\
50,9 \\
548,1\end{array}$ & $\begin{array}{r}51,8 \\
6,3 \\
3,2 \\
12,7 \\
8,1 \\
7,3 \\
4,0 \\
0,5 \\
5,6\end{array}$ \\
\hline 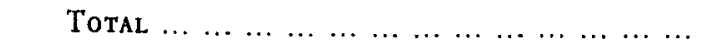 & $9.655,9$ & 100 \\
\hline
\end{tabular}

Como se podrá apreciar, tanto estos porcentajes como su representación geográfica reflejan las zonas de la clientela de pastel de la compañía Bernuy. Pero también, lo que es más importante, el mapa y ciertas características de la industria textil castellana a mediados del siglo xvr. 
P. Iradiel, el mejor conocedor de sus rasgos en la Edad Media, ha señalado cómo desde fines de dicho período en ésta se han producido toda una serie de transformaciones motivadas por los problemas y adaptaciones de la artesanía urbana y las mutaciones acaecidas en la demanda de tejidos y en la estructura de la artesanía textil. Ante ello, la pañería castellana, de modo semejante a la del resto de Europa, se comportó de diferentes formas: manteniendo la oferta de productos, al calor del crecimiento económico de los siglos XV y XVI, en competencia con la importación de telas extranjeras; desarrollando la artesanía rural, de menores costos de producción; y estimulando la penetración de los mercaderes-fabricantes de la ciudad en el campo, es decir, la preeminencia del capital comercial en la organización del trabajo artesano rural ${ }^{29}$.

No es extraño, pues, que en dichas centurias se mantenga la producción de paños de calidad media y alta destinados al consumo de los grupos sociales poderosos de las ciudades y del campo. Estos se visten con dichos tejidos, al igual que con los importados del noroeste de Europa o los de seda. Pero, sobre todo, vamos a asistir a la creciente difusión de artículos a bajo precio, producidos en medios urbanos y especialmente rurales. Aquí la figura del mercader-fabricante, el verlager, desempeña un papel fundamental al propulsar el sistema de producción por encargo.

El resultado de todo ello es la proliferación de centros textiles a partir de mediados del siglo $\mathrm{xv}$, donde la prosperidad imperante en el campo y la ciudad favoreció el aumento de la demanda. Así, dicho profesor señala diferentes zonas: Segovia; Cuenca; Toledo; Sevilla; Murcia; Córdoba; Granada; Cartagena, Lorca, Mula, Librilla, Aledo, Alhama, Caravaca, Molinaseca, Cieza. Villena y Yeste; Albacete, Jumilla, Alcaraz y Hellín: el C.mpo de Calatrava; el valle y la sierra de los Pedroches; Bujalance, Castro del Río y serranía de Córdoba; Burgos, Belorado, Val de Ezcaray, Valdelaguna y Neila; Palencia, Dueñas y Torquemada; Calahorra, Agreda, Osma y Sigüenza; Avila, Piedrahíta y Béjar; la Tierra de Segovia; etc. ${ }^{30}$. Junto a las tradicionales ciudades artesanales encontramos múltiples poblaciones rurales. En estas últimas, sus habitantes encontraron en la producción textil un complemento a sus ingresos agrícolas. Esto parece que fue más intenso en las áreas pastoriles donde la oferta de trabajo era abundante y donde el cultivo no ofrecía suficientes ingresos monetarios y no podía constituir una ocupación a tiempo completo.

El panorama no se modificará mucho en el siglo xvI. Los datos sacados de la contabilidad de burgaleses mercaderes del pastel presentan una clientela

\footnotetext{
${ }^{24}$ Iradiel (1983).

30 Iradicl (1974), pp. 103-118; Iradicl (1983), pp. 107-110.
} 
localizada en muchas de estas zonas. Incluso, aunque de manera indirecta, permiten establecer una jerarquía entre ellas según su importancia pañera. De ahí que destaquen aquellas que por el nivel de sus producciones han conseguido un mayor desarrollo, lo que les permite teñir sus tejidos con tintes caros como el pastel. Las cifras obtenidas las he plasmado en el mapa 1. En él apreciamos varias regiones textiles.

En primer lugar, tenemos unas zonas caracterizadas por la pañería rural. La principal de ellas era la que comprendía las áreas de Val de EzcarayCameros-La Demanda, a caballo entre las actuales provincias de La Rioja, Burgos y Soria. Aquí la clientela del pastel se localizaba en una multitud de pequeños núcleos (Vinuesa, Torrecilla de Cameros, Laguna de Cameros, Villoslada, Pedroso, Anguiano, Viguera, Fontecilla, Ojacastro, Yanguas, Muro, Villanueva, Brieva, Baños de Riotobía, Nalda, Lumbreras, Neila, Zaldierna y Navarrete) y otros algo mayores (Ezcaray, Belorado y Santo Domingo de la Calzada). Aquí lo característico son los pequeños compradores, muchos de los cuales son agricultores, pastores y mulateros -incluso practican las tres actividades simultáneamente-, a los que hay que añadir algunos casos de curas y escribanos de los lugares. El complemento de sus economías vendría dado por la artesanía pañera.

El pastel lo adquieren en Bilbao ${ }^{31} \mathrm{y}$, sobre todo, a los agentes de los Bernuy, que a tal fin se desplazaban hasta los pueblos. La contabilidad refleja que, a menudo, eran malos pagadores, por lo que la compañía procedía con frecuencia al embargo de paños y lana de los tejedores.

En suma, la información que ofrecen las cuentas de los Bernuy y también de los Lerma muestra a esta región con un tipo de economía muy diversificada y que en gran medida giraba en torno a la lana y su transformación ${ }^{32}$. Es una zona que, por otra parte, era uno de los principales sitios de abastecimiento de dicha materia para la casi totalidad de mercaderes de Burgos ${ }^{33}$. De igual manera producía carne para el abastecimiento urbano ${ }^{34}$.

También tienen un marcado acento rural los artesanos que encontramos en localidades de ambas vertientes del Sistema Central. Este es el territorio de las grandes Comunidades de Villa y Tierra de la Extremadura castellana.

${ }^{31}$ Hay que tener en cuenta la importancia de los mercaderes-arrieros de dicha zona, en especial los de Yanguas y Viguera. Lapeyre (1981), pp. 96 y 129.

32 Brumont (1980), p. 52; González Enciso (1984), y Ojeda San Miguel (1989).

33 Según la pesquisa que el corregidor de Burgos hizo de los libros de cuentas de los años 1547.49 de los principales mercaderes de la ciudad, la mayor parte de ellos habían efectuado compras de «sacas de Villoslada y Viguera». AGS, Consejo Real, Legajo 94-1.

34 Así, el mismo Diego de Bernuy Orense en 1547 compró a Juan de Vitoria, vecino de Ezcaray, 623 ovejas, borregos, carneros y morruecos y 2 perros. El, a su vez, se los vendió - menos 6 borregos y 4 ovejas que habían sido comidos por los lobos- a diversos vecinos de Santa Cruz de Juarros por $131.580 \mathrm{mrs}$. 


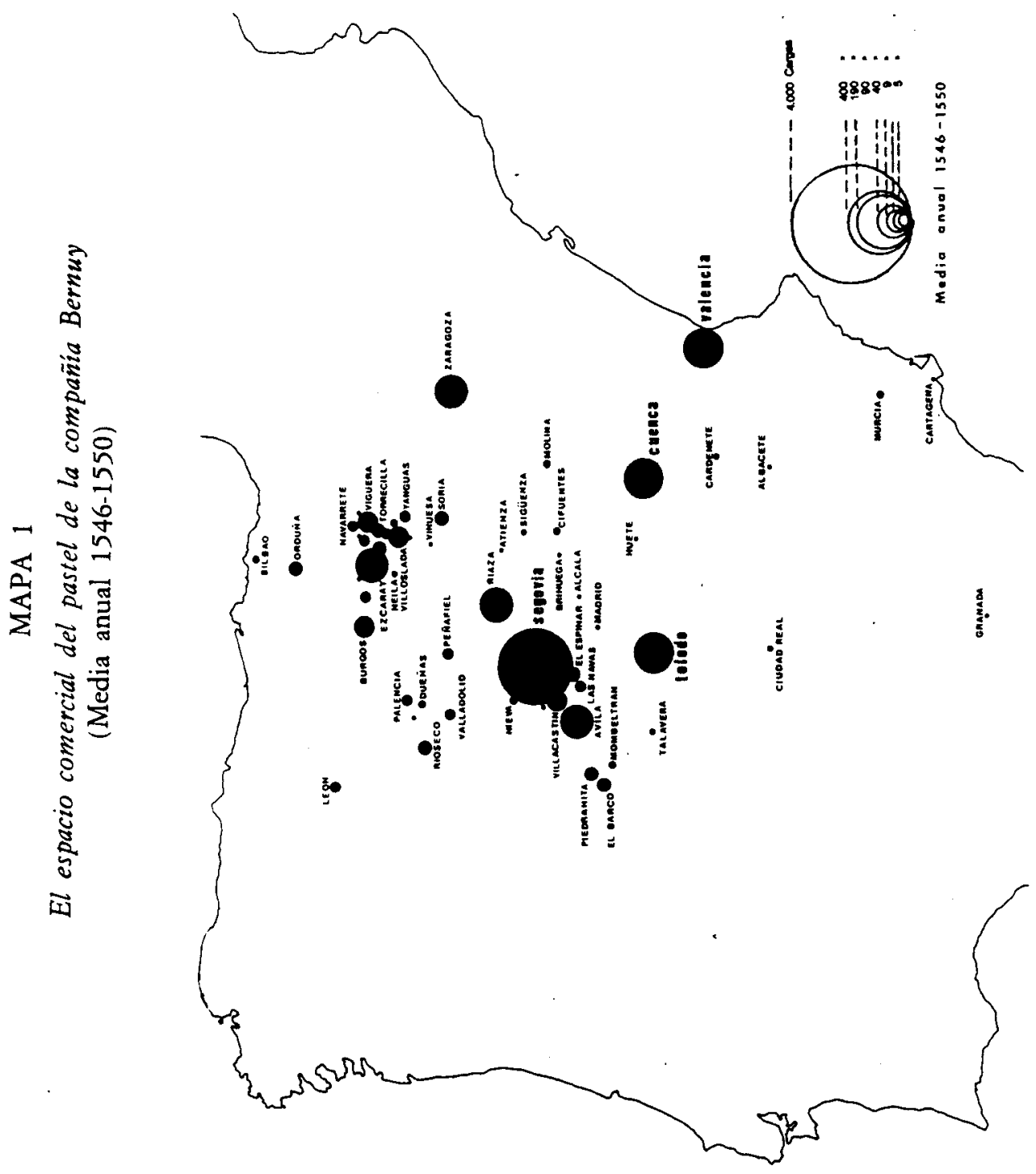


Aquí, en torno a dos ciudades, Avila y Segovia, tenemos una multitud de pequeños centros textiles, más o menos relacionados entre sí y respecto a dichas urbes: Villacastín, El Espinar, El Barco de Avila, Piedrahíta, Cifuentes, Molina, Mombeltrán, Sigüenza, Santa María de Nieva, Atienza, Riaza, Las Navas del Marqués, etc.

Gran parte de estos lugares estaban situados en las zonas de aprovisionamiento de lana de los mercaderes burgaleses, siendo incluso algunas de alta calidad ${ }^{35}$. Al igual que en $\mathrm{Val}$ de Ezcaray-Cameros, esta riqueza, unida a otra serie de razones, habría permitido una dedicación artesanal por parte de sus habitantes, la cual, en algunos casos, venía de antiguo. La diferencia respecto a la anterior región textil es que aquí contamos con unos centros urbanos que actúan no sólo como importantes núcleos artesanales, sino, sobre todo, como centros de comercialización y dirección de la pañería. Es el reino del Verlagssystem. Por medio de él se ha favorecido la fabricación de tejidos en estos pueblos, haciendo que una parte de sus habitantes, para su hechura, adquirieran el tinte a los grandes comerciantes del pastel. En estos centros rurales tenemos una clara penetración de mercaderes-fabricantes de la ciudad que compran y comercializan la producción.

Así, pues, la información contenida en la contabilidad de los comerciantes burgaleses Diego de Bernuy y Juan de Lerma nos muestra la importancia que a mediados del siglo xvi había adquirido la pañería rural. En este panorama destacan dos zonas más intensamente dedicadas a dicha actividad: Val de Ezcaray-Cameros y las dos vertientes del Sistema Central. Pero también con un marcado carácter rural creo que deben entenderse los artesanos que compran pastel en Cardenete, Huete, Talavera, Cuenca de Campos, Dueñas y Ampudia. Algunos son centros de tradición textil medieval, pero otros han cobrado auge a lo largo del siglo xvi. Estamos, en consecuencia, en los inicios de lo que ha venido en denominarse la protoindustrialización ${ }^{36}$. Como dice Iradiel, «se habría producido, pues, una afirmación en determinadas zonas de una industria textil rural con una articulación agrourbana del obraje de paños que favorece al capital comercial practicante del sistema de producción por encargo" ${ }^{37}$.

Aunque, como ha sido señalado, es muy difícil diferenciar la pañería rural de la urbana y mucho menos oponerlas entre sí, las cuentas de estos dos mercaderes señalan cinco principales centros textiles ciudadanos donde vendían sus cargas de pastel, bien a comerciantes, bien a artesanos: Zaragoza, Valencia, Toledo, Cuenca y Segovia.

\footnotetext{
${ }^{35}$ Basas Fornández (1963), pp. 235-252.

so Aracil (1981) y Kricdtc, Mudick y Schlumbohm (1986).

37 Iradiel (1983), p. 102.
} 
Los dos primeros — citados sólo en la contabilidad de Diego de Bernuyaparecen ocasionalmente en la documentación. En Zaragoza tenemos constancia de compras de tinte por parte del socio de la compañía Bernuy, Gabriel Çaporta. La mercancía llegaba por vía terrestre desde Toulouse a través de Somport y Canfranc, desconociéndose su posterior redistribución. Más importante era el mercado valenciano. Allí la familia tenía negocios destacables: compra de tejidos, conservas, seda en bruto, exportación de telas, terciopelos y cueros a Castilla y Lyon e importación de pastel desde los puertos de Narbona y Aigues-Mortes ${ }^{38}$. Su socio, Mosén Pero Roca, actuaba en dichas actividades conforme las instrucciones recibidas, pero también participaba con sus propios capitales. Sin embargo, en la contabilidad no aparecen las posteriores ventas del colorante.

Estos inconvenientes no existen para el conocimiento de la artesanía textil castellana. Aquí la información disponible es muy completa. Siguiendo en orden de importancia económica, podemos comentar algo de los centros pañeros urbanos de Castilla. En primer lugar, Toledo. En la ciudad del Tajo la compañía Bernuy tenía un agente/socio, Hernand Gómez de Acre, que era muy activo en la vida económica de la urbe. Le vemos comprando seda joyante de Murcia y Valencia y vendiendo paños y cueros nacionales y extranjeros. El era el encargado de traficar con el pastel de la familia (el 4 por 100) entre los artesanos de la ciudad y su región, presentando razón de sus actos al cajero de la sociedad. Por ello, sabemos que, amén de distribuir el tinte en pequeñas cantidades a artesanos urbanos, también lo efectúa con vecinos de Talavera, La Puente del Arzobispo, Ciudad Real, Almagro y Huceda.

El mercado conquense tenía para los Bernuy una ligera mayor importan. cia (el 7,3 por 100 de las ventas). En dicha ciudad, su agente Mateo Pellijero recibía el pastel llegado desde Cartagena/Murcia y lo distribuía entre los clientes. Entre ellos existe una gran uniformidad, ya que no hay grandes compradores. Sólo destacan algunos miembros de la familia de tintoreros de los Pedraza e Isabel de la Hoz, viuda de Alonso Martínez. De todas formas, la escasa importancia que tienen las ventas de pastel en Cuenca por parte de los Bernuy y los Lerma me induce a pensar que la pañería conquense a mediados del siglo xvi había dejado de tener el peso de épocas anteriores.

Por el contrario, la hegemonía textil castellana en dichos años recaía, sin duda, en Segovia ${ }^{39}$. La contabilidad, tanto de Diego de Bernuy como de Juan de Lerma y otros mercaderes burgaleses, muestra que allí estaban sus principales clientes. En el caso del primero, el gran comerciantes del pastel en la Europa del siglo Xvi, allá vendía el 51,8 por 100 de sus cargas traídas

${ }^{38}$ En 1546, el volumen de ingresos de dichos negocios en Valencia fue de $3.179 .870 \mathrm{mrs}$.

39 Le Flem (1976) y García Sanz (1987). 
a la península. Si a éstas sumamos el 6,3 por 100 que lo hacía en pueblos de la actual provincia, el predominio de Segovia es abosluto. Para Juan de Lerma, dicho mercado era de igual importancia, aunque aquí las diferencias respecto a Val de Ezcaray-Cameros son menores.

Dejando aparte estas peculiaridades de escasa relevancia económica, podemos decir que, a juzgar por las cifras de compraventa de pastel por parte de los mercaderes burgaleses - lo mismo puede decirse en el caso de la rubia ${ }^{40}$ - , la industria pañera segoviana era, con clara diferencia respecto a las restantes, la más importante de España a mediados del siglo xvi.

Como ya se señaló, Segovia no sólo era la principal consumidora de pastel de Castilla, sino también el centro redistribuidor para gran parte de ambas mesetas. Comerciantes y artesanos de Avila, Piedrahíta, Las Navas, El Barco, Medina de Rioseco, Medina del Campo, Valladolid, Madrid, etc., en dicha ciudad efectuaban sus compras. Todo ello determinó que en la capital segoviana la compañía de los Bernuy tuviera la mayor red organizativa de sus negocios. A la cabeza de ella estaban los hermanos Barrón, Pedro y, especial. mente, Mateo. Este tenía alquilada una casa para almacenar el pastel por la que pagaba anualmente la suma de $15.000 \mathrm{mrs}$. En ella se depositaban las cargas que cada año traían unas $1.000 / 1.100$ carretas, lo que sin duda suponía para la urbe un inmenso trasiego de transporte. De hecho, la compañía, para evitar los inconvenientes que dichos vehículos ocasionaban, pagaba al ayuntamiento $9.000 \mathrm{mrs}$. anuales para costear el arreglo y empedrado de las calles.

Si estas noticias nos hablan por sí solas de la importancia económica que en Segovia tenían los negocios de los Bernuy, he de añadir que las cuentas de la sociedad reflejan el pago anual de 133 jornales a obreros para efectuar las labores de descarga, remiendo y reparto de las balas de pastel. A ellos hay que sumar determinados criados fijos, maestros de ensayar, etc. Así, pues, pudemos decir que dicha compañía, a través de sus representantes, impulsaba en cierta manera el empleo en la ciudad. Incluso su inmersión en la vida social de ésta llegaba al punto de costear parte de gastos de procesiones o determinadas limosnas, cuyas cifras se incluían en las costas del pastel.

La clientela de los Bernuy en Segovia era muy amplia. Por ejemplo, en 1546, un año de grandes ventas, su número ascendió a 153 personas (Apéndice II). Si analizamos dicha relación —-muy semejante a la de los años posteriores y coincidente en algunos casos con la de Juan de Lerma- compro-

${ }^{40}$ Tanto la compañía de Diego de Bernuy como la de Juan de Lerma apenas se dedicaron a comercializar con rubia u otros colorantes, siendo el volumen de dichos negocios insignificante. A modo de ejemplo, en 1549, los Bernuy vendieron 635 arrobas y 17 libras de rubia de Flandes, que habían comprado al mercader burgalés Francisco Maldonado, por valor de $339.981 \mathrm{mrs}$. El 91 por 100 de dichas ventas fue en Segovia. 
bamos la gran variedad de compradores. Por una parte, encontramos entre ellos a miembros de las poderosas familias segovianas, fabricantes de paños y con responsabilidades políticas en el concejo: los Avila, los Cornoça, los Asenjo, los Serrano, los Riofrío, los Temporal, los Ximena o los Curiel ${ }^{41}$. Pero, junto a ellos, hay una multitud de clientes que adquieren pequeñas cantidades de tinte. En algunos casos desconocemos su oficio, pero serían personas vinculadas de alguna manera con la artesanía textil y que elaborarían anualmente unos pocos paños.

Esta diversidad de compradores del colorante permite señalar, a falta de otra información de contraste, que en la industria pañera segoviana no hay síntomas que nos hagan afirmar la existencia de un monopolio o de un claro predominio de los grandes maestros o las fuertes «empresas». Más bien, el panorama que muestran las cuentas de los mercaderes burgaleses es la multiplicidad de pequeños talleres que coexisten con otros mayores. Los primeros, localizados en los arrabales de la ciudad e incluso en los pueblos de su término, mantendrían con los segundos interrelaciones económicas y sociales características del sistema de producción por encargo.

\section{CONCLUSIONES}

Hemos visto en estas páginas la importancia del comercio y consumo del pastel en la España de mediados del siglo xvi. Tanto en el caso del mercader Juan de Lerma y, sobre todo, en el de Diego de Bernuy Orense, el volumen de maravedís manejados en dicho tráfico es impresionante y superior a las cifras conocidas de otros negociantes castellanos. Pero estas mismas cantidades -en 1546, millón y medio de maravedís por el primero y 77.480 .042 por el segundo $(52.880 .261$ en Castilla, 3.848 .202 en Valencia y Zaragoza, 10.678.076 en Londres y 10.073.503 en Flandes) - nos revelan el poder financiero de estas compañías, dado que gran parte de los pagos se hacían diferidos.

Dichas sumas nos están indicando que el comercio del pastel era tan importante como el de otros productos, especialmente la lana, que de manera tradicional se ha venido indicando como el género por excelencia intercambiado por los burgaleses. Incluso he comprobado que el comercio de dicho colorante era uno de los que generaba más ganancias. En el caso del gran mercader Diego de Bernuy he calculado que en 1546 obtuvo con la venta

4' Ruiz Martín (1965), pp. 271-273, y Carande (1987), pp. 505.508. Es posible que algunos de estos mercaderes-hacedores de paños vendieran parte de sus compras de pastel a tintoreros de otras zonas de España. Dato que se ha de contrastar con la consulta de la documentación segoviana. 
de 10.252 cargas de pastel en Castilla un beneficio neto del 36 por 100 . Cifra que es claramente superior a la que obtenían otros negociantes en esos mismos años con el tráfico de la lana (en torno al $10-15$ por 100) o la importación de paños extranjeros (13 por 100). Esto nos ayudaría a comprender el hecho que la compañía Bernuy pueda ser considerada como una de las más importantes de Europa en el siglo xvi y perfectamente equiparable a las más conocidas de Italia o Alemania ${ }^{42}$.

Asimismo, la comercialización del pastel dentro de la península, y de manera especia en Castilla, permite aproximarnos al conocimiento de la industria pañera en España en el Quinientos. Su redistribución refleja tanto el espacio comercial de dicho tinte y, en consecuencia, la geografía de los centros textiles. En ella se yuxtaponen las zonas urbanas y las rurales, aunque las vinculaciones entre ambas son muy intensas al imperar el sistema de producción por recargo. Entre todas ellas destaca Segovia y su área de influencia, que son los mejores clientes de los mercaderes burgaleses. Hegemonía que ha sido ocasionada al dominar sus mercaderes-fabricantes los métodos del Verlagssystem.

Interrelación entre el capital mercantil y artesanado que no se da en el caso de los comerciantes de Burgos. Estos se dedican exclusivamente a vender el pastel u otros tintes, pero nunca intervienen en los procesos de producción ni comercializan los paños. En sus libros de contabilidad, Juan de Lerma y Diego de Bernuy sólo anotaron unas pocas ventas de tejidos nacionales, los más de ellos conseguidos mediante el embargo de aquellos clientes malos pagadores. Caso contrario acontece con los paños y telas extranjeros (ingleses, flamencos, bretones o normandos), tradicional objeto de intercambio por los mercaderes de la Cabeza de Castilla y de cuyo comercio fueron consumados maestros desde la Edad Media. No es extraño, pues, que los intereses de la oligarquía burgalesa fueran muy distintos a los de las ciudades artesanales. Hecho que hunde sus raíces en los años finales de la Edad Media ${ }^{43}$.

42 Casado Alonso (en prensa, a).

${ }^{43}$ A este respecto, véase Casado Alonso (1987 y 1988). 


\section{BIBLIOGRAFIA}

Alvarez García, C. (1988): «Diego de Ordónez, hombre de negocios y clérigo. Restos de su archivo privado (1497-1520)», Revista Española de Financiación y Contabilidad, vol. XVII, núm. 53, pp. 31-114.

ARACIL, R. (1983): «Industria rural i proto-industrial: aspectes generals i bibliografics», Estudis d'Història Contemporania del Pais Valenciá, núm. 4, pp. 257-279.

Barkham, S. (1980-1981): «Burgos Insurance for Basque Ships: Maritime Policies from Spain, 1547-1592», Archivaria, núm. 11, pp. 87-91.

Basas Fernández, M. (1963): El Consulado de Burgos en el siglo XVI, Madrid.

Bernard, J. (1968): Navires et gens de mer à Bordeaux (vers 1400-vers 1550), París, 3 vols.

Brumont, F. (1986): «La Rioja en el siglo xvi», II Coloquio sobre Historia de La Rioja, vol. II, Logroño.

Brunelle, G. K. (1989): «Immigration, Assimilation and Success: Three Families of Spanish Origin in Sixteenth Century Rouen», The Sixteentb Century Journal, vol. XX, núm. 2, pp. 203.219.

Carande, R. (1987): Carlos $V$ y sus banqueros, vol. I: La vida económica de Castilla (1516-1556), Barcelona (2. ed.).

Casado Alonso, H. (1987): Señores, mercaderes y campesinos. La comarca de Burgos a fines de la Edad Media, Valladolid.

- (1988): «Oligarquía urbana, comercio internacional y poder real: Burgos a fines de la Edad Media», en A. Rucquoi (ed.), Realidad e imágenes del poder. España a fines de la Edad Media, Valladolid, pp. 325-347.

- (1989): «Comercio internacional y seguros marítimos en Burgos en la época de los Reyes Católicos», Congresso Internacional «Bartolomeu Dias e a sua epoca», Universidad de Oporto, Oporto, vol. III.

- (en prensa, a): «Finance et Commerce international au milieu du XVIe siècle: La Compagnie des Bernuy», Annales de Midi, Toulouse.

Caster, G. (1962): Le commerce du pastel et de l'épicerie à Toulouse (de 1450-environ a 1561), Toulouse.

De Poerck, G. (1951): La draperie médiévale en Flandre et en Artois: tecbrique et terminologie, Brujas, 3 vols.

Fortea Pérez, J. I. (1981): Córdoba en el siglo XVI. Las bases demográficas y económicas de una expansión urbana, Córdoba.

García Sanz, A. (1987): "Mercaderes hacedores de paños en Segovia en la época de Carlos $\mathrm{V}$ : organización del proceso productivo y estructura del capital industrial», Hacienda Pública Española, núms 108-109, pp. 65-79.

Gil ABAD, P. (1983): Junta y Hermandad de la Cabaña Real de Carreteros de BurgosSoria, Burgos.

González EnCiso, A. (1984): «La industria dispersa en la Sierra de Cameros, 1700-1840m, Cuadernos de Invesitgación. I Coloquio sobre Historia de La Rioja, tomo X, Logroño.

González Hernando, J. M. (1983): «Los "Libros de Cuentas" de la familia Ruiz, mercaderes-banqueros de Medina del Campo (1551-1606)», Actas del I Congreso sobre Archivos Económicos de Entidades Privadas, Madrid, pp. 23-45.

HeRnÁndez Esteve, E. (1988): «Comentario histórico-contable sobre los libros de cuentas de Diego Ordónez», Revista Española de Financiación y Contabilidad, vol. XVII, núm. 53, pp. 223-276.

HuXLEY, S. (1984): «Los vascos y las pesquerías transatlánticas (1517-1713)", Itsasoa 3. Los vascos en el marco atlántico norte. Siglos XVI y XVII, San Sebastián, pp. 26-165.

Iradiel. Murugarren, P. (1974): Evolución de la industria textil castellana en los siglos XIII-XVI. Factores de desarrollo, organización y costes de producción manufacturera en Cuenca, Salamanca.

- (1983): «Estructuras agrarias y modelos de organización industrial precapitalista en Castilla», Stvdia Historica, vol. I, núm. 2, pp. 87-112. 
Jones Mathers, C. (1988): «Family Partnerships and International Trade in Early Modern Europe: Merchants from Burgos in England and France, 1470-1570», Bussiness History Review, vol. 62, pp. 367-397.

Kriedte, P.; Medick, Н., у Sсhlumboнm, Н. (1986): Industrialización antes de la Industrialización, Barcelona.

LAPEYRE, H. (1981): El comercio exterior de Castilla a través de las aduanas de Felipe II, Valladolid.

LE Flem, J. P. (1976): «Vraies et fausses splendeurs de l'industrie textile ségovienne (vers 1460-vers 1650)», Produzione, Commercio e Consumo dei Panni di Lana (nei secoli XII-XVIII), Florencia, pp. 525.536.

OJeda San Miguel, R. (1989): "Un documento para el análisis de una crisis textil: Ezcaray a comienzos del siglo XIX», Revista de Estudios Regionales, núm. 23, pp. 243-253.

Ruiz Martín, F. (1965): "La empresa capitalista en la industria textil castellana durante los siglos xvi y xvir", III International Conference of Economic History, Munich, pp. 267-276.

Torres Fontes, I. (1976): «Genoveses en Murcia (siglo xv)», Miscelánea Medieval Murciana, vol. II, pp. 69.118 .

WolfF, Ph. (1954): Commerce et marchands de Toulouse (vers 1350-vers 1450), París. 


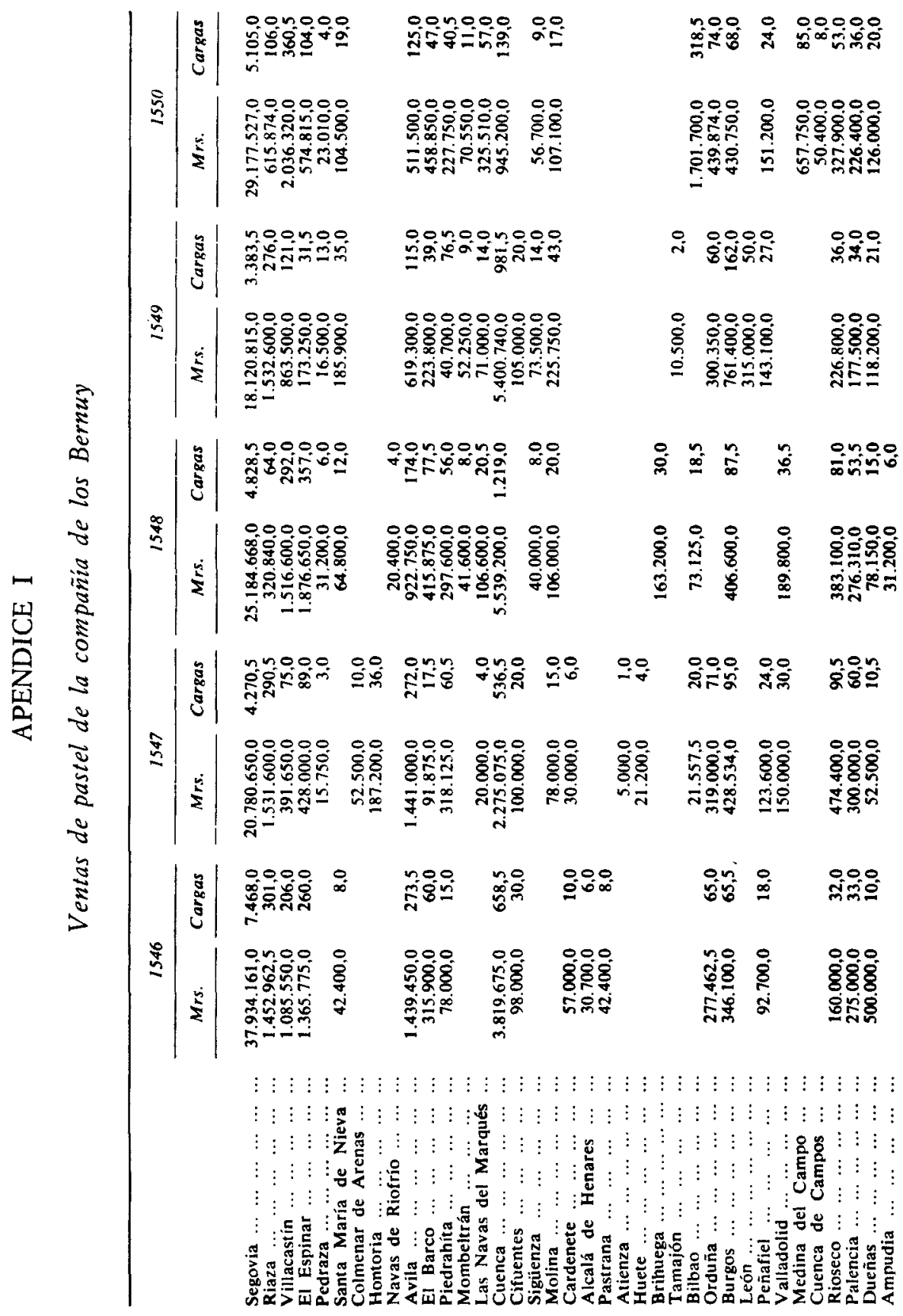




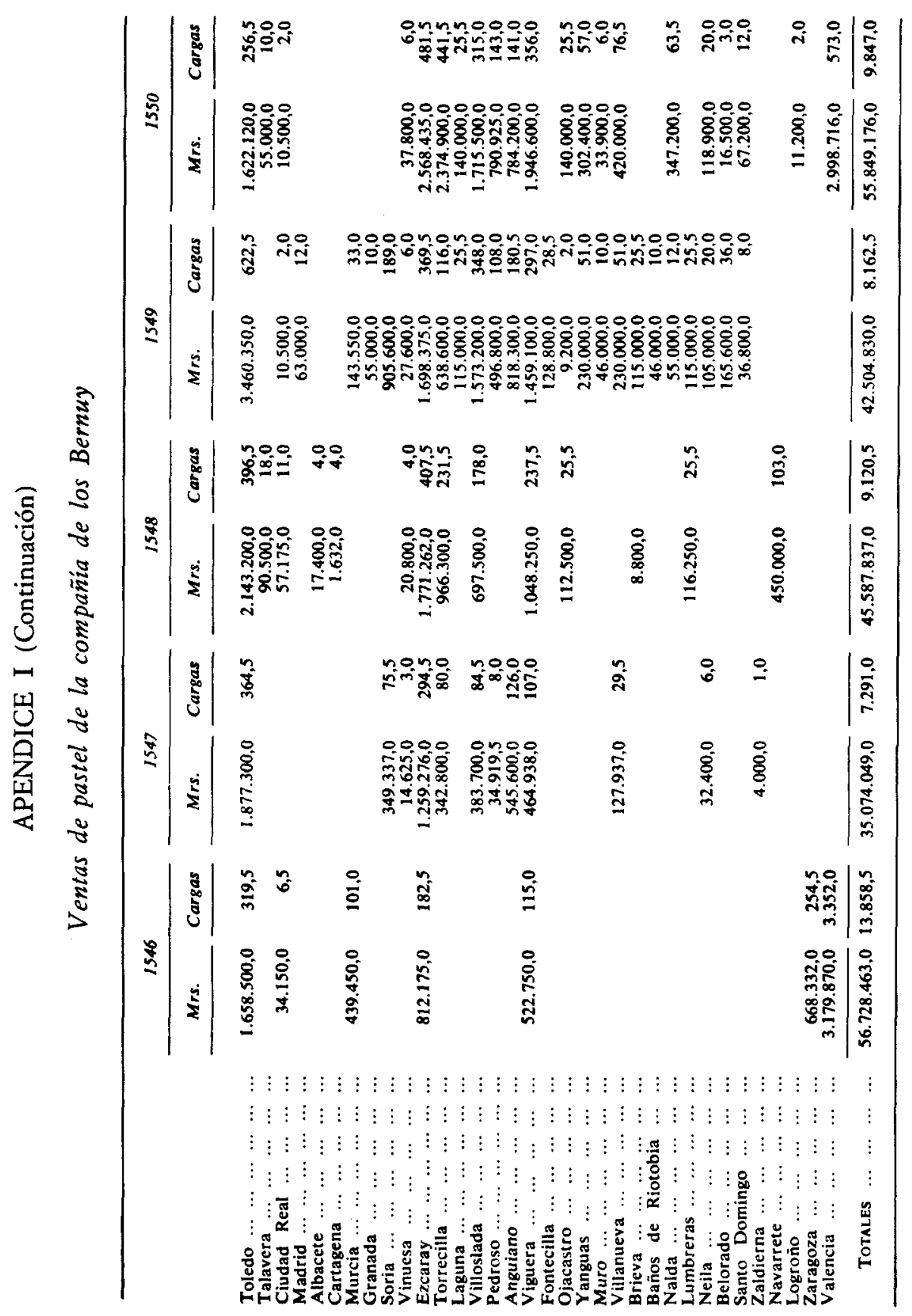




\title{
APENDICE II
}

\author{
Ventas de pastel a vecinos de Segovia por Diego de Bernuy \\ (Año 1546)
}

Compradores

Aguinaga, Pedro de

Alava

Alcalá, Juan de

Alonso de Segovia, Francisca (viuda de Diego Lope de San $\begin{array}{lllllllllllllll}\text { Miguel }) & \ldots & \ldots & \ldots & \ldots & \ldots & \ldots & \ldots & \ldots & \ldots & \ldots & \ldots & \ldots & \ldots & \ldots\end{array}$

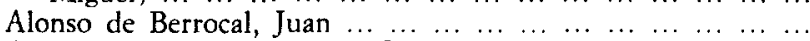

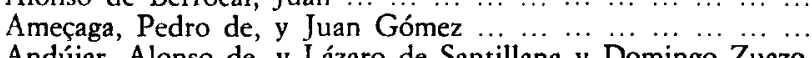
Andújar, Alonso de, y Lázaro de Santillana y Domingo Zuazo. Angulo, Pedro de

Arreo, Antonio de

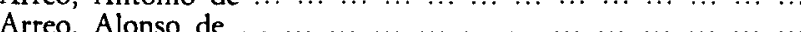

Asenjo el Mozo, Antonio

Asenjo, Antón (padre de Francisco Äsenjo)

Asenjo, Francisca (viuda de Juan de Dueñas) ... . . . . . . . . .

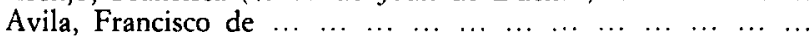

Avila, Isabel de (viuda de Pedro de Peñaranda) ... ... ... ...

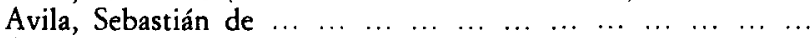

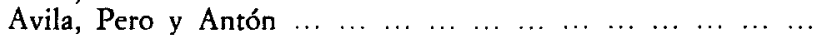

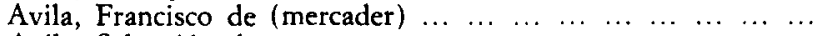

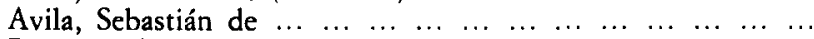

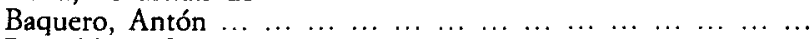

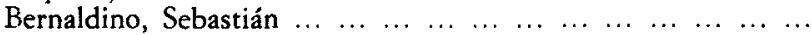

Bonifaz, Esteban y Melchor $\ldots \ldots \ldots \ldots \ldots \ldots$

Buitrago, Cristóbal

$\begin{array}{lllllllll}\text { Burboa, Pedro y Hernando de } & \ldots & \ldots & \ldots & \ldots & \ldots & \ldots & \ldots & \ldots\end{array}$

Canto, Pedro del, y Elvira Alonso (su abuela) ... . . . . . . . . .

Cavallos, Bernardino de, y Francisco de Sepúlveda ... ... ...

Cerezo, Francisco (maestre del tinte) $\ldots \ldots \ldots \ldots \ldots \ldots \ldots \ldots$

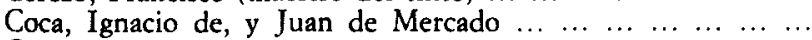

$\begin{array}{llllllllllll}\text { Cornoça, Juan de } & \ldots & \ldots & \ldots & \ldots & \ldots & \ldots & \ldots & \ldots & \ldots & \ldots & \ldots\end{array}$

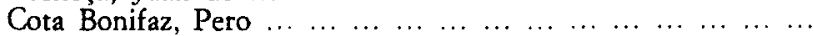

Cuevas, Juan de $\ldots \begin{array}{llllllllllllll} & \ldots & \ldots & \ldots & \ldots & \ldots & \ldots & \ldots & \ldots & \ldots & \ldots & \ldots & \ldots & \ldots\end{array}$

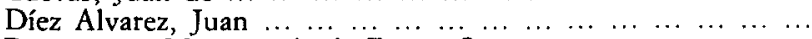

Domínguez, Mari (viuda de Frutos Serrano) $\ldots \ldots \ldots \ldots \ldots$

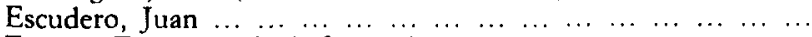

España, Francisco de (calcetero) $\ldots \ldots \ldots \ldots \ldots \ldots$

Espinar, María del (viuda de Gerónimo Bonifaz) $\ldots \ldots \ldots \ldots$.

Espinar, María del, y Pablo Bonifaz (su hijo) ... ... ... ... ...

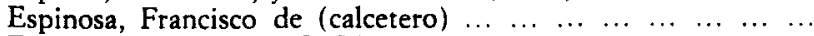

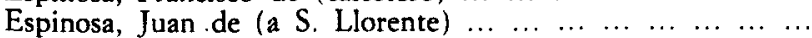

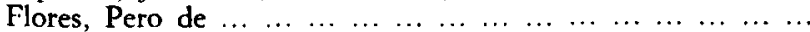

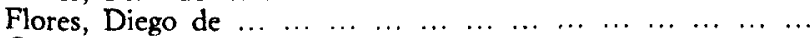

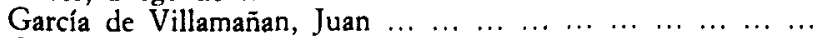

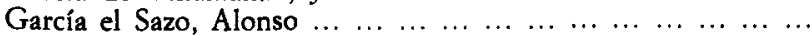

Gómez, Antón

\begin{tabular}{|c|c|}
\hline Cargas & Mrs. \\
\hline 43,5 & 217.500 \\
\hline 29,5 & 153.400 \\
\hline 160,5 & 848.700 \\
\hline 2,0 & 10.200 \\
\hline 37,5 & 191.950 \\
\hline 128,0 & 645.000 \\
\hline 20,0 & 105.000 \\
\hline 16,0 & 84.000 \\
\hline 6,0 & 32.250 \\
\hline 136,0 & 703.300 \\
\hline 106,5 & 542.950 \\
\hline 71,0 & 371.150 \\
\hline 161,0 & 833.500 \\
\hline 7,5 & 37.000 \\
\hline 109,0 & 566.125 \\
\hline 254,5 & 1.271 .300 \\
\hline 110,0 & 571.700 \\
\hline 107,5 & 557.800 \\
\hline 60,0 & 316.625 \\
\hline 12,0 & 63.000 \\
\hline 40,0 & 206.000 \\
\hline 44,0 & 228.000 \\
\hline 20,0 & 105.000 \\
\hline 20,0 & 101.960 \\
\hline 60,0 & 312.000 \\
\hline 44,0 & 228.700 \\
\hline 55,0 & 285.750 \\
\hline 60,0 & 312.000 \\
\hline 20,0 & 102.000 \\
\hline 121,5 & 629.425 \\
\hline 35,0 & 175.000 \\
\hline 5,0 & 26.500 \\
\hline 2,0 & 10.500 \\
\hline 140,0 & 725.200 \\
\hline 10,0 & 52.500 \\
\hline 12,0 & 61.200 \\
\hline 10,0 & 51.000 \\
\hline 71,0 & 372.500 \\
\hline 20,0 & 105.000 \\
\hline 30,0 & 157.500 \\
\hline 73,0 & 383.900 \\
\hline 14,0 & 72.600 \\
\hline 32,0 & 167.700 \\
\hline 3,0 & 15.750 \\
\hline 20,0 & 105.000 \\
\hline
\end{tabular}




\section{APENDICE II (Continuación)}

\section{Ventas de pastel a vecinos de Segovia por Diego de Bernuy (Año 1546)}

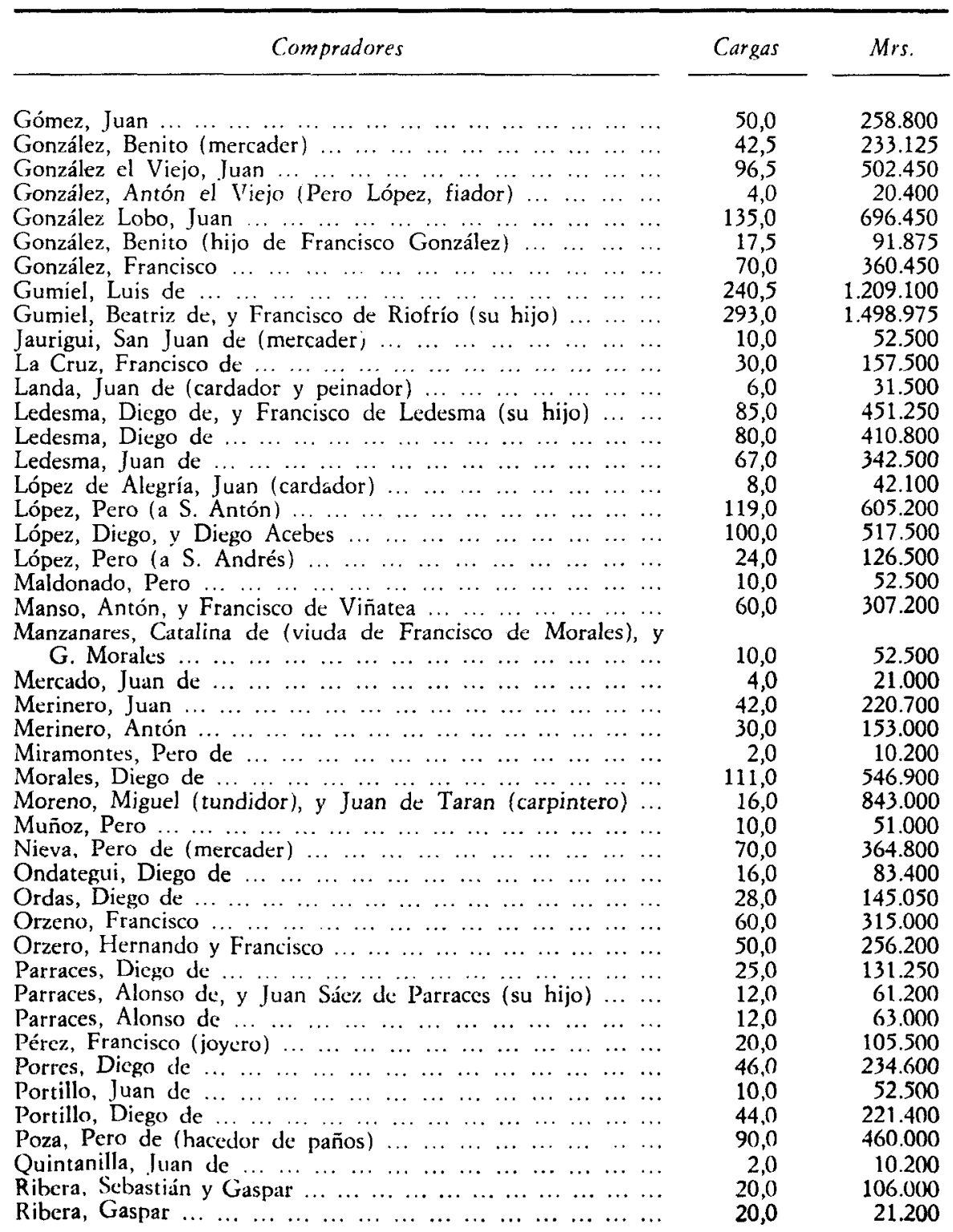




\section{APENDICE II (Continuación)}

Compradores

Ribera, Juan de (maestre del tinte)

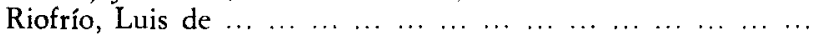

Rodríguez, Benito, y Francisco López, v. ${ }^{\circ}$ El Espinar ... ... . .

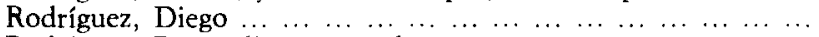

Rodríguez, Bernardino (mercader) $\ldots \ldots \ldots \ldots \ldots \ldots \ldots \ldots$

Ruiz de Aranguren, Juana (viuda de Antonio de Zamora) .... ...

Sáenz Maldonado el Mozo, Francisco

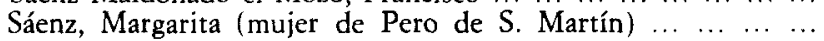

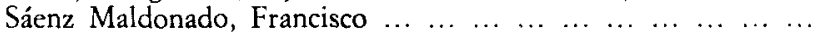

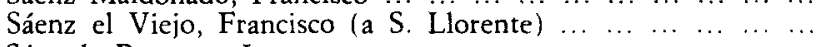

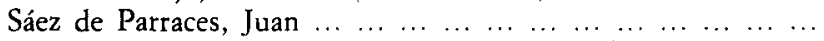

Sáez, Margarita (viuda de Pero S. Martín Avila) ... $\ldots \ldots \ldots$

Sáez, Francisco (a S. Llorente)

Salamanca, Antonio de (mercader)

Salazar, Bartolomé de.

Salcedo, Antonio de

San Antón, Llorente de (tejedor) $\ldots \ldots \ldots \ldots \ldots \ldots$

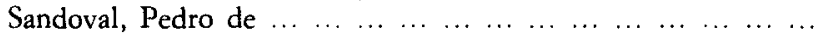

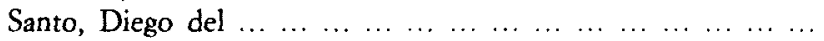

Santo, Diego del, y Juan de Çornoça $\ldots \ldots \ldots \ldots \ldots \ldots \ldots$

Secadura, Tomé de

Segovia, Juan de $\ldots \ldots \ldots \ldots \ldots \ldots \ldots \ldots$

Segovia, Francisca de (viuda de Diego López de S. Miguel) ...

Segovia, Miguel y Bernardino de ....

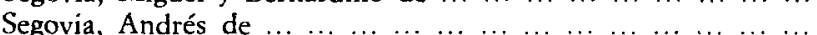

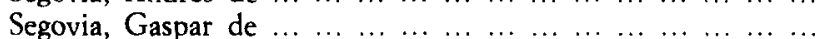

Segovia, Catalina de (viuda de Pero de Fuentes) ... . . . . . . .

Segovia, Francisco de, y Pero Cota Bonifaz (su hijo) .........

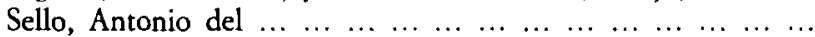

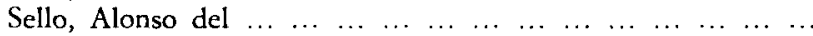

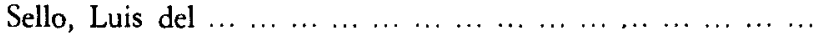

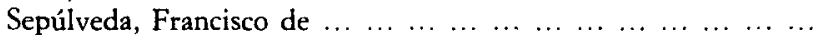

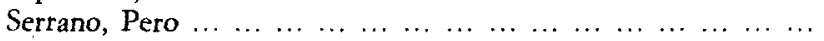

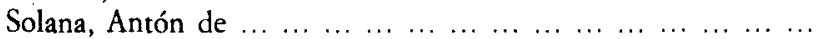

Soto, Lázaro de (escribano) $\ldots \ldots \ldots \ldots \ldots \ldots$

Sustayta, Bernardino de, y $\mathrm{P}$. de Mesa (cardero) ... ... ... ...

Temporal, Pedro

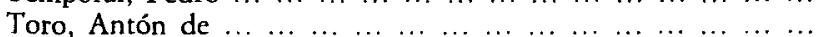

Trinidad, María de la (viuda de Domingo de Vitoria) ... ... ...

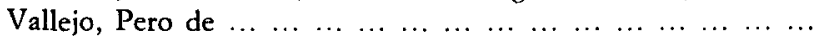

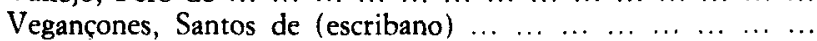

Velasco, Isabel de (mujer de Juan de Vitoria) ..............

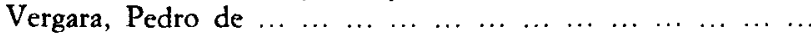

Vergara, Pedro de, y Bernardino de Segovia $\ldots \ldots \ldots \ldots \ldots$

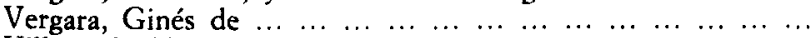

Villarreal, Alvaro de $\ldots \begin{array}{llllllllllll}\ldots & \ldots & \ldots & \ldots & \ldots & \ldots & \ldots & \ldots & \ldots & \ldots & \ldots & \ldots\end{array}$

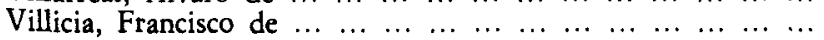

\begin{tabular}{|c|c|}
\hline Cargas & Mrs. \\
\hline 10,0 & 52.500 \\
\hline 36,0 & 186.600 \\
\hline 20,0 & 105.000 \\
\hline 98,5 & 511.750 \\
\hline 23,5 & 122.550 \\
\hline 23,5 & 119.850 \\
\hline 40,0 & 212.500 \\
\hline 50,0 & 262.500 \\
\hline 2,0 & 10.500 \\
\hline 50,0 & 266.000 \\
\hline 69,0 & 359.650 \\
\hline 30,0 & 153.400 \\
\hline 37,0 & 189.100 \\
\hline 54,0 & 280.500 \\
\hline 2,0 & 10.600 \\
\hline 105,0 & 543.450 \\
\hline 10,0 & 52.500 \\
\hline 12,0 & 63.000 \\
\hline 30,0 & 57.500 \\
\hline 16,0 & 82.000 \\
\hline 22,0 & 116.000 \\
\hline 10,0 & 52.500 \\
\hline 20,0 & 105.000 \\
\hline 105,0 & 857.850 \\
\hline 25,0 & 127.900 \\
\hline 12,0 & 61.600 \\
\hline 69,0 & 354.750 \\
\hline 90,5 & 733.500 \\
\hline 100,0 & 318.750 \\
\hline 100,0 & 159.375 \\
\hline 6,0 & 30.675 \\
\hline 14,0 & 73.800 \\
\hline 268,0 & $1,373.350$ \\
\hline 100,0 & 519.500 \\
\hline 10,5 & 52.500 \\
\hline 8,0 & 42.400 \\
\hline 354,0 & 1.795 .625 \\
\hline 8,0 & 42.000 \\
\hline 38,0 & 197.100 \\
\hline 34,0 & 169.500 \\
\hline 56,0 & 288.100 \\
\hline 20,0 & 105.000 \\
\hline 12,0 & 63.000 \\
\hline 10,0 & 51.400 \\
\hline 20,0 & 106.000 \\
\hline 60,0 & 311.500 \\
\hline 21,0 & 107.100 \\
\hline
\end{tabular}


APENDICE II (Continuación)

\begin{tabular}{|c|c|c|}
\hline Compradores & Cargas & Mrs. \\
\hline Vinatea el Mozo, Francisco de, y Juan Calvo .............. & 10,0 & 52.500 \\
\hline $\begin{array}{llllll}V_{i t} & \end{array}$ & 30,0 & 153.000 \\
\hline Vitoria, Diego de, y Melchor Bernaldo (tundidor) & 6,0 & 31.800 \\
\hline 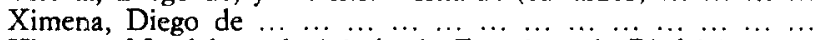 & 50,0 & 249.500 \\
\hline Ximena, Magdalena de (viuda de Francisco de Riofrío) ... ... & 150,0 & 751.150 \\
\hline Zuazo, Domingo de, y Lázaro de Santillana y A. Andújar ... & 4,0 & 21.200 \\
\hline
\end{tabular}

Nota: La carga de pastel equivalía en torno a los 179 kilogramos. 